\title{
RETRACTED_Formation and properties of Zr-based bulk quasicrystalline alloys with high strength and good ductility
}

\author{
A. Inoue, T. Zhang, M.W. Chen, T. Sakurai, J. Saida, and M. Matsushita \\ doi: 10.1557/JMR.2000.0316, Published by the Materials Research Society, 31 January 2011.
}

This article ${ }^{1}$ has been retracted by the Editor-In-Chief.

Figures 1, 2, 5, 20, and 21 were earlier published in the authors' publications in Materials Transactions, JIM, ${ }^{2}$ Applied Physics Letters ${ }^{3}$ (also retracted), and Materials Science and Engineering. ${ }^{4}$ No permission was obtained from the publishers to reprint the figures.

The authors also self-plagiarized substantial portions from all of the above publications.

This retraction has no bearing on the previously published work, and the results stand as presented.

\section{REFERENCES}

1. A. Inoue, T. Zhang, M.W. Chen, T. Sakurai, J. Saida, and M. Matsushita: RETRACTED-Formation and properties of
Zr-based bulk quasicrystalline alloys with high strength and good ductility. J. Mater. Res. 15, 2195-2208 (2000). doi: 10.1557/ jmr.2000.0316.

2. A. Inoue, T. Zhang, J. Saida, M. Matsushita, M.W. Chen, and T. Sakurai: High strength and good ductility of bulk quasicrystalline base alloys in $\mathrm{Zr}_{65} \mathrm{Al}_{7.5} \mathrm{Ni}_{10} \mathrm{Cu}_{17.5-x} \mathrm{Pd}_{x}$ system. Mater. Trans., JIM 40, 1137-1143 (1999). doi: 10.2320/matertrans1989.40.1137.

3. A. Inoue, T. Zhang, M.W. Chen, and T. Sakurai: Ductile quasicrystalline alloys. Appl. Phys. Lett. 76, 967 (2000). doi: 10.1063/ 1.125907.

4. A. Inoue, C. Fan, J. Saida, and T. Zhang: High-strength Zr-based bulk amorphous alloys containing nanocrystalline and nanoquasicrystalline particles. Sci. Technol. Adv. Mater. 1, 73-86 (2000). doi: 10.1016/s1468-6996(00)00009-7. 